\title{
Creative Learning Setting: Autonomous Self-Regulatory Support as Smoking Prevention
}

\author{
Christine S. Hedler, Franz X. Bogner \\ Centre of Math \& Science Education, University of Bayreuth, Bayreuth, Germany \\ Email: christine.geier@uni-bayreuth.de
}

Received November 22 $2^{\text {nd }}, 2012$; revised December $28^{\text {th }}, 2012$; accepted January $7^{\text {th }}, 2013$

\begin{abstract}
298 fifth graders' motivational styles were measured using the Treatment Self-Regulatory Questionnaire prior to and six weeks following a creative student-centred anti-smoking intervention in secondary schools. In this paper we can clearly show that our creative learning setting leads to a significant increase in autonomous motivation and a decrease in controlled motivation. Autonomously motivated pupils had less or no experience with cigarettes. Pupils' main guesses about when or why young people smoke, are curiosity or being together with others. We conclude that such a short-term preventative intervention with different creative educational methods positively affects pupils' health self-regulation.
\end{abstract}

Keywords: Autonomous Motivation; Creative Learning Stations; Health Education; Self-Regulation; Smoking Prevention

\section{Introduction}

Considerable research has already focused on the optimal uptake of smoking prevention among adolescents (Bruvold, 1993; Furr-Holden et al., 2004; Maziak et al., 2003). Schoolbased smoking prevention seems to be a suitable setting to reach a cohort in the decisive developmental stages (Dijk et al., 2007; Lynagh et al., 1997). Particularly, within the narrow time frames available at school, an integration of a brief anti-smoking education lesson is suggested to have effective impact. Such interventions must aim to prevent early risk behaviours, potential future use and to stop current use. The main focus should be on pupils' thinking about the issues as well as on making their own decisions about how to behave. Smoking prevention must go beyond a pure factual knowledge transfer and promote general skills to foster health consciousness and social reinforcement (Botvin et al., 2003).

From the pupils' point of view the teaching style is clearly as important as the message itself. To take this into consideration, student-oriented approaches should offer the instructor a variety of methods suitable for differing learning content (Randler \& Bogner, 2006; Sturm \& Bogner, 2008). Smoking prevention unit will especially support many competences, such as functional and communication competence, critical thinking and decision-making as well as skills in resisting social influences (Botvin et al., 1984; 1990). The efficiency of such an open interactive learning environment has been shown in many studies (e.g. Christianson \& Fisher, 1999; Lord, 1997). A specific student-oriented approach is learning at stations, where pupils autonomously work in small teams (Sturm \& Bogner, 2008). It provides hands-on learning experiences, requires that pupils practice essential knowledge and skills, frees them to observe and assess their learning. Furthermore, it is more likely to meet the needs, especially creativity, of individual pupils.

The present study takes into account the fact that smoking behaviour is a dynamic process including sequential developmental stages (Kremers et al., 2004). Mayhew et al. (2000) defined and reviewed these stages as follows: Children who have never smoked and never considered smoking in the future are in the pre-contemplation stage. They might cognitively be predisposed to start smoking later on, in so far as they sometimes modify their beliefs and attitudes, for instance, following exposure to the media or the influence of role models (contemplation or preparatory stage). When trying their first cigarette they are in the trial stage, in which case strong peer influence could be of great concern. The subsequent experimenting stage is accompanied by increasing smoking behaviour, creating an individuals' self-image as a smoker. The final stages are the regular stage and daily smoking stage.

The reason for starting smoking at all is principally related to many predictor variables such as smoking parents or siblings and the number of smoking friends or peers (Järvelaid, 2004). This was an important reason for selecting the fifth grade for the present study. In the German system this grade encompasses the transition stage from elementary school to secondary school, confronting pupils with another learning environment, new teachers and new peers. In order to obtain potential reasons why pre-adolescents begin to smoke, Kobus (2003) pointed to the relevance of knowing how they observe their environment and how they evaluate others. The question "what do pupils think about the situations in which young people smoke?" is therefore of central interest.

To answer this question we should consider different styles of motivation why pupils begin smoking and how non-smoking could be fostered. First, controlled motivation means that one smokes because of external pressure or control and not by confidence that smoking is one's personal choice. Second, unmotivated persons are unwilling to learn or do anything about healthy behaviour, especially smoking. In this case, pupils should implement anti-smoking messages as autonomy-supportive. As shown by a study of parent styles autonomous support positively predicted autonomous self-regulation (Grolnick \& Ryan, 1989). This is the most self-determined form of moti- 
vation that support positive health-care outcomes, even behavioural changes and an awareness of perceived choice without external influence (Deci \& Ryan, 1985; Williams et al., 1999; 2002). As a consequence, their level of autonomous motivation and in best case, their future non-smoking behaviour should be engaged. If pupils are more autonomously motivated, they might better resist social peer pressure and their personal risk of starting to smoke might be lower.

Many studies regard cognitive achievement as the most important measure for the efficacy of educational prevention (Rundall \& Bruvold 1988, Tobler et al. 2000). However, Rosendahl et al. (2005) showed that it is not generally linked to pupils' future smoking behaviour. The effectiveness of a preventative intervention depends rather on individual self-esteem, behavioural self-regulation and positive outcomes in health related autonomous motivation (Jackson, 1997). The Treatment Self-Regulatory Questionnaire (TSRQ) has been shown to be a useful empirical measure of motivational styles (Ryan \& Connell, 1989). It evaluates the degree of autonomous self-regulation with regard to specific healthy behaviour; several studies have discussed its effectiveness (Levesque et al., 2007; Williams et al., 2002). We focused in particular on gender-specific differences because they are viewed as an important variable in defining pupils' perceptions and behavioural beliefs (Nic Gabhainn \& Kelleher, 2000).

There is a distinct lack of studies of how young pupils evaluate the smoking behaviour of other young people or even of how any brief educational prevention impacts on pupils' autonomous health motivation and self-regulation. The aims of our present study are to assess fifth graders' attitudes towards smoking, their current smoking status and their intention to smoke. We quantify the efficacy of the intervention with different creative educational methods on pupils' autonomous motivation by using the TSRQ.

\section{Methods}

\section{Participants and Procedure}

298 fifth graders of five randomly selected Bavarian secondary schools ("Gymnasium") participated in the present study. The participation was voluntary (a cover letter was sent to all schools) and teachers as well as pupils were informed about the confidentiality of their data. The attrition rate due to missing data was $17 \%$ of the original sample; these pupils were excluded from the evaluation. Participants' mean age was 10.41 $( \pm 0.54)$ years. 124 girls and 174 boys were involved.

The anti-smoking intervention was implemented identically in classroom settings (fourteen classes). Classes were randomly selected. The classroom teachers were introduced to the study's procedure and instructed not to discuss smoking before the end of data collection. The pupils were not aware of any details of the intervention.

\section{Educational Prevention Programme}

The preventative programme involved student-centred instruction, was implemented as a block course during school time and lasted for 130 minutes. It consisted of ten obligatory and three optional learning stations. The individual creative learning stations dealt both with smoking issues (e.g. cigarette ingredients and their relevant health consequences, physiological harm) and with general skills in resisting smoking (e.g. smoking refusal techniques, peer pressure, media influence; see Table 1).

This interactive anti-smoking programme was designed to be implemented in daily school lessons. The pupils worked at the learning stations autonomously in small groups of two to three members by using a coloured workbook and different information material. Every learning station had a corresponding chapter

Table 1.

Ten main (A-J) and three optional (K-M) learning stations with different creative educational methods.

\begin{tabular}{|c|c|}
\hline Description & Creative educational method \\
\hline "Path of breathing air" & $\begin{array}{l}\text { - Draft the path of breathing air } \\
\text { - Solve a brain twister }\end{array}$ \\
\hline "What's inside the fag?" & $\begin{array}{l}\text { - } \quad \text { Fill in a cloze } \\
\text { - Stick on relevant hazard symbols and warnings }\end{array}$ \\
\hline Carbon monoxide: "The labyrinth" & $\begin{array}{l}\text { - Draw a labyrinth with the left and right hand within a given time } \\
\text { - } \quad \text { Compare them with those of a smoker (fill in tables) }\end{array}$ \\
\hline Tar: "Where does all the smoke remain?" & $\begin{array}{l}\text { - Depict the spots of blown out cigarette smoke on a tissue } \\
\text { (with and without deep trag) and compare them } \\
\text { - Look carefully at different lung pictures }\end{array}$ \\
\hline "Health hazard of smoking" & - Puzzle game with red flags from cigarette packages and human organs (tinker) \\
\hline Learn to say "NO!" & $\begin{array}{l}\text { - Role game: confrontation with peer pressure } \\
\text { - Learn arguments with a comic pattern and give feedback to each other }\end{array}$ \\
\hline Create your own "No-smoking-button". & $\begin{array}{l}\text { - } \quad \text { Create a slogan against smoking } \\
\text { - } \quad \text { Tinker a button with different materials and pencils }\end{array}$ \\
\hline "I carry my life in my hand!" & - Listen to a story (radio play) about self-determination \\
\hline How much money is "consumed"? & $\begin{array}{l}\text { - } \quad \text { Calculate the cost of smoking } \\
\text { - } \quad \text { Flip the amount in a catalogue for pupils }\end{array}$ \\
\hline "How does smoking advertising operate?" & - $\quad$ Compare two coloured advertising poster \\
\hline "Just why smoking?!" & - Fill in a comic about smoking reasons of young and adult people \\
\hline
\end{tabular}


in the workbook. A sample solution was lying on the teacher's desk for pupils' self-control. The participants often had to discuss problems within their groups, to handle equipment and to make notes of their individual group findings in the workbook. The teacher simply had the role of a supervisory facilitator and was able to focus on special problems or individual pupils. Another detailed description of the learning stations' content, its effectiveness in pupils' cognitive achievement and intrinsic motivation concerning the influence of learning environment (comparing two learning settings: "school" and "out-of-school") will be provided elsewhere (see Author $1 \&$ Author 2). Due to our general test design we did not address fifth graders of secondary schools others than Gymnasium or a control group (e.g. traditional lesson).

\section{Empirical Measures}

We used several items and batteries (see below). The test was administered anonymously and required approximately 15 minutes to complete. Question sequences were randomized per test (pre and follow-up) to prevent test effects (an individual anonymous number code of each participant affected clear matching). The pupils were unaware of time schedules or repetitions. The ethical approval of the study was carried out by the review board of ministry of education.

\section{Smoking Measures}

Current smoking status was measured at two test schedules: at a pre-test (T-1; Cronbach's alpha 0.70$)$ one week prior to intervention and at a follow-up test $(\mathrm{T}-2$; alpha $=0.74)$ six weeks later. The items were (following Carlhoff, 1982): "Have you ever tried a cigarette?", "Have you ever smoked a whole cigarette?" and "Have you smoked often?" rated "Yes" or "No". We measured the future intention to smoke with one item: "Do you think you will smoke in five years?" The pupils were categorized into four relevant types (according to Mayhew et al., 2000 and Kremers et al., 2004), see Table 2.

Another item was "If you have already tried smoking, or have smoked, it was because of..." with five possible responses: "curiosity", "bravado", or "invitation by friends", "parents" or "siblings". A further question concerned pupils' appraisal of young peoples' reasons or motives to smoke, namely "In which situations do you think young people smoke?" with thirteen items to answer with "Yes" or "No" (e.g. "after a meal"). Multiple answers were possible but a maximum of five permitted. We evaluated the pupils' attitude towards the new smoke-free school policy by means of a grading score: from 1 = very good, over $3=$ I don't care to $5=$ not good at all.

\section{Self-Regulation Measures}

The TSRQ, modified for pre-adolescents, measures motive- tional styles for specific health-related behaviour, in our case, the intention to smoke. It is useful in examining when or why pupils would or would not smoke, assessed using the following statement: "The reasons I would not smoke are...". It contained three subscales: the autonomous regulatory style (six items, e.g. "Because I personally believe it is the best thing for my health"); the controlled regulatory style (six items, e.g. "Because others would be upset with me if I smoke"); and amotivation (three items, e.g. "I really don't know why"; Ryan and Connell, 1989; Williams et al., n.d.). A Likert scale ranging from $1=$ not true at all, over $3=$ somewhat true, to $5=$ very true was employed. The test was applied twice: in a pre-test $(\mathrm{T}-1$; Cronbach's alpha $=0.75)$ about one week prior to the intervention and in a follow-up test $(\mathrm{T}-2$; alpha $=0.77)$ six weeks later. A "Relative Autonomous Motivation Index" was calculated from the TSRQ response, computed as the average for the autonomous regulatory style minus the average for the controlled regulatory style (Williams et al., n.d.).

\section{Statistical Analysis}

SPSS 16.0 was employed in all the calculations and Sigma Plot 11.0 to create the figure. We applied non-parametric tests due to a non normal distribution of the scores. A p-value of less than 0.05 was used as the significance threshold. Differences in the proportion of variables were tested using Chi-square analysis. Gender-differences were examined where possible.

\section{Results}

\section{Pupils' Smoking Behaviour}

Most pupils belonged to the Precontemplators (89.9\%; see definitions in Table 2) at both time schedules. A few participants $(1.3 \%)$ of both genders belonged to the Contemplators and $7.4 \%$ belonged to the Triers. Significantly more boys had already tried cigarettes at $\mathrm{T}-1(\mathrm{chi}$ square $=11.636 ; p=0.001)$. Only $1.3 \%$ of the participants are Experimenters.

The most frequently stated reason for trying or experimenting with cigarettes was "curiosity" (73.1\%) and secondly "because of friends" $(23.1 \%)$. The other reasons were less popular: "bravado" (11.5\%), "because of parents" (7.7\%) or "siblings" (3.9\%). The percentages may not add up to $100 \%$ because of multiple responses.

The findings of pupils' estimation about when or why young people smoke are presented for the total sample $(N=298)$. Only a few pupils chose the motives "to occupy my hands" $(5.7 \%)$, "for better concentration" $(5.7 \%)$ and "after a meal" $(8.1 \%)$. Other possible motives scored low to moderate, namely "unpleasant situation" (19.5\%), "relaxation" (23.2\%), "restlessness" $(23.2 \%)$, "worry or anger" $(27.5 \%)$, "boredom" (37.6\%), "by habit" (47.3) and "to be more attractive" (55.7\%).

Table 2.

Categories of smoking status.

\begin{tabular}{ll}
\hline \multicolumn{1}{c}{ Stage } & \multicolumn{1}{c}{ Definition } \\
\hline Pre-contemplation stage & Non-smokers who do not intend to smoke. \\
Contemplation stage & Non-smokers, but with the intention to smoke in the next five years. \\
Trial stage & Tried only a puff or at most one cigarette. \\
Experimenting stage & Smoke on an experimental basis (more than once). \\
\hline
\end{tabular}


About two-thirds considered "stress" (67.1\%), "being together with others" $(84.2 \%)$ and "discos/parties" $(89.9 \%)$ as the main typical situations in which young people would smoke.

Gender differed in four situations, with girls yielding higher scores regarding "stress" (Mann-Whitney U Test: $Z=-2.692 ; p$ $=0.007)$ and "unpleasant situation" $(Z=-2.035 ; p=0.042)$. Boys yielded higher scores for the motives "by habit" $(Z=$ $-2.978 ; p=0.003)$ and "relaxation" $(Z=-3.257 ; p=0.001)$.

\section{Analysis of Self-Regulation}

Regarding the three TSRQ subscales, the autonomous regulatory style showed high scores for both time schedules and no significant differences regarding pre- and follow-up tests $(N=$ 298; $Z=-0.402 ; p=0.688$ ). The controlled regulatory style showed significant differences $(Z=-7.628 ; p<0.001)$. Mean scores for the amotivation style were relatively low and dropped significantly after six weeks $(Z=-5.764 ; p<0.001$; Figure 1).

The "Relative Autonomous Motivation Index" was 1.355 in the pre-test and 1.708 in the follow-up test, an increase from baseline to follow-up of $20.7 \%$ towards more pupils' autonomous regulation.

The TSRQ scores were gender-dependent in almost all cases; girls showed comparatively lower scores. In the pre-test, significant gender differences were obtained for the autonomous regulatory style (Mann-Whitney $U$ Test: $Z=-2.184 ; p=0.029$ ) and the amotivation style subscales $(Z=-1.992 ; p=0.046)$, whereas the controlled regulatory style subscale did not differ ( $Z=-1.572 ; p=0.116)$. At follow-up, we found significant gender differences in the autonomous regulatory style $(Z=$ $-2.363 ; p=0.018)$ and controlled regulatory style subscales $(Z$ $=-2.602 ; p=0.009)$. We found no significant difference, but a strong tendency in the amotivation style subscale $(Z=-1.947$; $p=0.051)$.

\section{Discussion}

The main findings of our study are that curiosity or being together with others are pupils' main guesses about when or why young people smoke. Only few fifth graders had already experimented with cigarettes. The intervention affected posi-

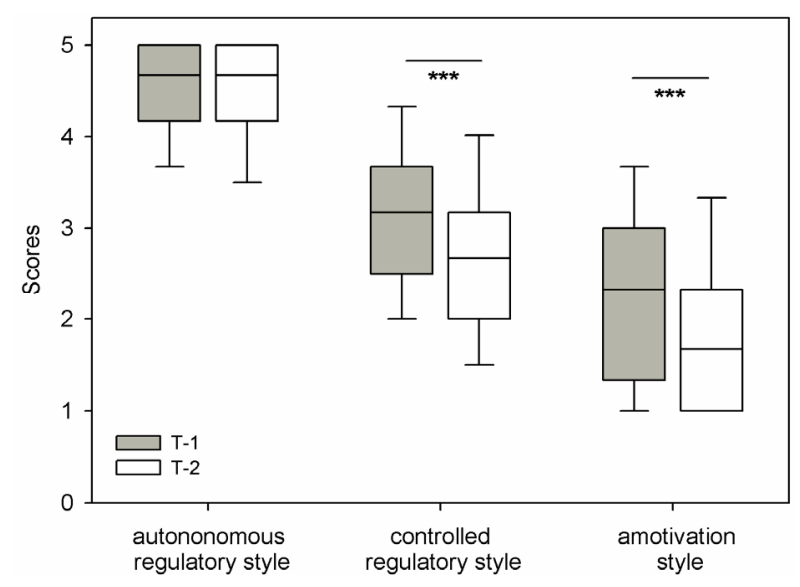

Figure 1.

Differences in the mean scores of the TSRQ subscales $(1=$ not true at all to $5=$ very true) for the two test times: pre-test (T-1) and follow-up test $(\mathrm{T}-2 ; N=298)$. tively their autonomous motivation and decreased their controlled motivation and amotivation.

Fortunately, most of the participants were non-smokers with no intention to smoke. This number is lower than in other studies (e.g. Milton et al., 2008), maybe because of the young age group. The participants are younger than the initiation age of approximately 11.6 years (BZgA, 2004), because especially at this early age an anti-smoking education programme may support non-smoking behaviour (Furr-Holden, et al., 2004). More boys had already tried cigarettes, in confirmation of other studies suggesting that boys try cigarettes at an earlier age than girls (Järvelaid, 2004; Lucas \& Lloyd, 1999; Mayhew et al., 2000). Our sample contained only a small number of already experimenting pupils and no pupils smoked regularly or daily, which is a reassuring result for the target group of fifth graders.

The main self-reported reason for trying or experimenting with cigarettes was curiosity, a finding that is in line with other studies which have reported curiosity as a significant predictor and critical factor of progression toward smoking (Dijk et al., 2007; Milton et al., 2008; Pierce et al., 2005). Curiosity associates strongly with having friends who smoke, due to their strong influence, i.e. they communicate their subjective positive effects of smoking and this may provoke curiosity in nonsmokers. The transition process from non-smoker to experimenter is characterized by stronger peer than family influences (Mayhew et al., 2000). Reasons for trying cigarettes vary across studies, but often give family, peers and neighbourhood as the strongest influence (Järvelaid, 2004; Kremers et al., 2004). These results suggest that a variety of factors are associated with the developmental stages of smoking (Mayhew et al., 2000).

The present study also explored children's evaluation of situations when young people smoke. Pupils selected the situations "being together with others" and "discos/parties" as typical smoking situations in confirmation of other studies reporting high external influence and peer pressure on pre-adolescents (Kobus, 2003). In addition, "Stress" was one of the favourite reasons given, maybe because of impressions from older people, films and media etc., with the imagery as an accurate reflection of reality (McCool et al., 2001). This supports other findings that many children believe that smoking can help to reduce stress and alleviate negative mood states (e.g. Freeman et al., 2005). The simple fact that many potential reasons for smoking were not selected, like smoking "after a meal", points to the need for specific education about the scope of this subject and the smoking image. Our results show gender differences in the reasons given for smoking (see e.g. Lucas \& Lloyd, 1999). Girls selected "stress" and "unpleasant situations", whereas boys chose other aspects, like "relaxation" and "by habit". Future smoking prevention should be tailored to these varying evaluations.

Brown et al. (2007) showed that a student-centred preventative programme can be successful; in our study this success is achieved by the increase in autonomous motivation. The pupils already had high autonomous self-regulation prior to the intervention. Fortunately, the decrease in the controlled regulatory style and in the amotivation style implies that the intervention affected positively pupils' self-regulation and that it was autonomously supportive. The resulting differences might be caused of pupils' creative satisfaction with the intervention itself, expressed in a very positive motivation. This is in line with Lord (2001) who pointed to pupils' preference for a stu- 
dent-oriented approach and their contentment with such learning experiences. Similarly, Tobler (2000) noted interactive programmes to be more effective than non-interactive ones. Especially for girls, fostering self-regulation will be of future concern in educational prevention because of the social sensibility to the smoking environment (Mayhew et al., 2000).

Some study limitations should be mentioned. Although the attrition rate was relatively low it could be that those who dropped out had a higher risk of starting to smoke. Because of the few already trying and experimenting pupils in our study, it was not possible to examine the influence of the intervention on higher or lower at-risk pupils. Children at higher risk of beginning smoking need comparatively more and long-term help in developing social and refusal skills and autonomous support (Epps \& Manley, 1993). It point to a need for further follow-up data to measure longer-term effects of such a preventative creative intervention on smoking-related attitudes (Lynagh et al., 1997). As Freeman et al. (2005) has established, experimenting with cigarettes often occurs after the transition from elementary to secondary school, because some of the new peers are already smoking. Therefore, there is an implication for future interventions to measure the influence of autonomous support on pupils' autonomous motivation for not smoking in the long term. Another limitation of the study should be mentioned: we could not obtain any measures of a control group due to the test design. Although Israel et al. (1995) showed that the assignment to control groups may not always be feasible or desirable; we were not able to apply these specific items to a control group without any intervention. Furthermore, there is still a need to examine the effect of the attitudes in a smoking prevention approach without any group work. However, such newer orientations had a comparatively greater impact on attitudinal and behavioural changes and should definitely be supported (Bruvold, 1993).

To conclude, anti-smoking interventions should be tailored to pupils' developmental stages, targeted to their varied experiences and motivational styles (Milton et al., 2008). Primary prevention should always foster autonomous motivation in health behavior. As shown, meaningful smoking prevention with different creative educational methods motivates individuals and reduces the proportion of at-risk pupils. Careful attention should always be given to factors that may affect early onset users, e.g. external control. Curiosity is the most significant predictor and needs most attention. Interventions in a creative learning setting should generally focus on different health-related profiles as well as on different risks of starting to smoke. Our study shows that even a short-term student-centred preventative intervention positively affects pupils' autonomous self-regulation and health-related attitudes, and possibly influences their future healthy behaviour.

\section{Acknowledgements}

This research was supported by the EU-grant BIOHEAD (Biology, Health and Environmental Education for better Citizenship). The authors would like to thank S. Gross for useful comments on this paper and to M. Wiseman for statistical assistance and valuable discussion.

\section{REFERENCES}

Botvin, G. J., Baker, E., Filazzola, A. D., \& Botvin, E. M. (1990). A cognitive-behavioral approach to substance abuse prevention: One year follow-up. Addictive Behaviors, 15, 47-63. doi:10.1016/0306-4603(90)90006-J

Botvin, G. J., Baker, E., Renick, N. L., Filazzola, A. D., \& Botvin, E. M. (1984). A cognitive-behavioral approach to substance abuse prevention. Addictive Behaviors, 9, 137-147. doi:10.1016/0306-4603(84)90051-0

Botvin, G. J., Griffin, K. W., Paul, E., \& Macaulay, A. P. (2003). Preventing tobacco and alcohol use among elementary school students through life skills training. Journal of Child \& Adolescent Substance Abuse, 12, 1-17. doi:10.1300/J029v12n04 01

Brown, S., Birch D., Thyagaraj S., Teufel J., \& Phillips C. (2007). Effects of a single-lesson tobacco prevention curriculum on knowledge, skill identification and smoking intention. Journal of Drug Education, 37, 55-69. doi:10.2190/638J-J7G2-4T58-28JU

Bruvold, W. H. (1993). A meta-analysis of adolescent smoking prevention programs. American Journal of Public Health, 83, 872-880. doi:10.2105/AJPH.83.6.872

BZgA (2004). Drug affinity among young people in the Federal Republic of Germany 2004. Köln: BZgA.

Carlhoff, H.-W. (1982). Rauchgewohnheiten bei Schüler des 4. Schuljahres. In DHS (Hrsg.), Rauchen oder Gesundheit. Politische, präventive und therapeutische Aspekte. Hamburg, 88.

Christianson, R. G., \& Fisher, K. M. (1999). Comparison of student learning about diffusion and osmosis in constructivist and traditional classrooms. International Journal of Science Education, 21, 687-698. doi: 10.1080/095006999290516

Deci, E. L., \& Ryan, R. M. (1985). Intrinsic motivation and self-determination in human behaviour. New York: Plenum Publishing Co.

Dijk, F., de Nooijer, J., Heinrich, E., \& de Vries, H. (2007). Adolescents' view on smoking, quitting and health education. Health Education, 107, 114-125. doi:10.1108/09654280710731539

Epps, R. P., \& Manley, M. W. (1993). Prevention of tobacce use during childhood and adolescence. Cancer Supplement, 72, 1002-1004. doi:10.1002/1097-0142(19930801)72:3+<1002::AID-CNCR2820721 $309>3.0 . \mathrm{CO} ; 2-\mathrm{G}$

Freeman, D., Brucks, M., \& Wallendorf, M. (2005). Young children's understanding of cigarette smoking. Addiction, 100, 1537-1545. doi:10.1111/j.1360-0443.2005.01195.x

Furr-Holden, C. D. M., Ialongo, N. S., Anthony, J. C., Petras, H., \& Kellam, S. G. (2004). Developmentally inspired drug prevention: Middle school outcomes in a school-based randomized prevention trial. Drug and Alcohol Dependence, 73, 149-158. doi:10.1016/j.drugalcdep.2003.10.002

Grolnick, W. S., \& Ryan, R. M. (1989). Parent styles associated with children's self-regulation and competence in school. Journal of Educational Psychology, 81, 143-154. doi:10.1037/0022-0663.81.2.143

Israel, B. A., Cummings, K. M., Dignan, M. B., Heaney, C. A., Perales, D. P., Simons-Morton, B. G., \& Zimmermann, M. A. (1995). Evaluation of health education programs: Current assessment and future directions. Health Education Quarterly, 22, 364-389. doi:10.1177/109019819402200308

Jackson, C. (1997). Initial and experimental stages of tobacco and alcohol use during late childhood: Relation to peer, parent, and personal risk factors. Addicitve Behaviors, 22, 685-698. doi:10.1016/S0306-4603(97)00005-1

Järvelaid, M. (2004). Adolescent tobacco smoking and associated psychosocial health risk factors. Scandinavian Journal of Primary Health Care, 22, 50-53. doi:10.1080/02813430310000988

Kobus, K. (2003). Peers and adolescent smoking. Addiction, 98, 37-55. doi:10.1046/j.1360-0443.98.s1.4.x

Kremers, S. P. J., de Vries, H., Mudde, A. N., \& Candel, M. (2004). Motivational stages of adolescent smoking initiation: Predictive validity and predictors of transitions. Addictive Behaviors, 29, 781-789. doi:10.1016/j.addbeh.2004.02.007

Levesque, C. S., Williams, G. C., Elliot, D., Pickering, M. A., Bodenhamer, B., \& Finley, P. J. (2007). Validating the theoretical structure of the Treatment Self-regulation Questionnaire (TSRQ) across three different health behaviors. Health Education Research, 22, 691-702. doi: $10.1093 /$ her/cyl148 


\section{S. HEDLER, F. X. BOGNER}

Lord, T. R. (1997). A comparison between traditional and constructivist teaching in college biology. Innovative Higher Education, 21, 197216. doi: $10.1007 / \mathrm{BF} 01243716$

Lord, T. R. (2001). 101 reasons for using cooperative learning in biology teaching. The American Biology Teacher, 63, 30-38. doi: $10.2307 / 4451027$

Lucas, K., \& Lloyd, B. (1999). Starting smoking: Girls' explanations of the influence of peers. Journal of Adolescence, 22, 647-655. doi:10.1006/jado.1999.0260

Lynagh, M., Schofield, M. J., \& Sanson-Fisher, R. W. (1997). School health promotion programs over the past decade: A review of the smoking, alcohol and solar protection literature. Health Promotion International, 12, 43-60. doi:10.1093/heapro/12.1.43

Mayhew, K. P., Flay, B. R., \& Mott, J. A. (2000). Stages in the development of adolescent smoking. Drug and Alcohol Dependence, 59, 61-81. doi:10.1016/S0376-8716(99)00165-9

Maziak, W., Rzehak, P., Keil, U., \& Weiland, S. K. (2003). Smoking among adolescents in Muenster, Germany: Increase in prevalence (1995-2000) and relation to tobacco advertising. Preventive Medicine, 36, 172-176. doi:10.1016/S0091-7435(02)00020-8

McCool, J. P., Cameron, L. D., \& Petrie, K. J. (2001). Adolescent perceptions of smoking imagery in film. Social Science \& Medicine, 52, 1577-1587. doi:10.1016/S0277-9536(00)00270-7

Milton, B., Woods, S. E., Dugdill, L., Porcellato, L., \& Springett, R. J. (2008). Starting young? Children's experiences of trying smoking during pre-adolescence. Health Education Research, 23, 298-309. doi:10.1093/her/cym027

Nic Gabhainn, S., \& Kelleher, C. C. (2000). School health education and gender: An interactive effect? Health Education Research, 15, 591-602. doi:10.1093/her/15.5.591

Pierce, J. P., Distefan, J. M., Kaplan, R. M., \& Gilpin, E. A. (2005). The role of curiosity in smoking initiation. Addictive Behaviors, 30,
685-696. doi:10.1016/j.addbeh.2004.08.014

Randler, C., \& Bogner, F. X. (2006). Cognitive achievements in identification skills. Journal of Biological Education, 40, 1-5.

Rosendahl, K. I., Galanti, M. R., Gilljam, H., \& Ahlbom, A. (2005). Knowledge about tobacco and subsequent use of cigarettes and smokeless tobacco among Swedish adolescents. Journal of Adolescent Health, 37, 224-228. doi:10.1016/j.jadohealth.2004.08.021

Rundall, T. G., \& Bruvold, W. H. (1988). A meta-analysis of schoolbased smoking and alcohol use prevention programs. Health Education Quarterly, 15, 317-334. doi:10.1177/109019818801500306

Ryan, R. M., \& Connell, J. P. (1989). Perceived locus of causality and internalization: Examining reasons for acting in two domains. Journal of Personality and Social Psychology, 57, 749-761. doi: 10.1037/0022-3514.57.5.749

Sturm, H., \& Bogner, F. (2008). Student-oriented versus teacher-centred: The effect of learning at workstations about birds and bird flight on cognitive achievement and motivation. International Journal of Science Education, 30, 941-959. doi:10.1080/09500690701313995

Tobler, N. S., Roona, M. R. Ochshorn, P., Marshall, D. G., Streke, A. V., \& Stackpole, K. M. (2000). School-based adolescent drug prevention programs: 1998 meta-analysis. The Journal of Primary Prevention, 20, 275-336. doi:10.1023/A:1021362620740

Williams, G. C., Cox, E. M., Kouides, R., \& Deci, E. L. (1999). Presenting the facts about smoking to adolescents-Effects of an autonomy-supportive style. Archives of Pediatrics \& Adolescent Medicine, 153, 959-964. doi:10.1001/archpedi.153.9.959

Williams, G. C., Gagné, M., Ryan, R. M., \& Deci, E. L. (2002). Facilitating autonomous motivation for smoking cessation. Health Psychology, 21, 40-50. doi:10.1037/0278-6133.21.1.40

Williams G. C., Ryan, R. M., \& Deci, E. L. (n.d.) Health care, SDT packet. URL (last checked 18 December 2010).

http://www.psych.rochester .edu/SDT/measures/hc_description.php 